\title{
Acquisition of lymph node, but not distant metastatic potentials, by the overexpression of CXCR4 in human oral squamous cell carcinoma
}

\author{
Daisuke Uchida, Nasima-Mila Begum, Yoshifumi Tomizuka, Takashi Bando, \\ Ammar Almofti, Hideo Yoshida and Mitsunobu Sato
}

Second Department of Oral and Maxillofacial Surgery, Tokushima University School of Dentistry, Kuramoto, Tokushima, Japan

\begin{abstract}
Recently, it has been suggested that chemokine/receptor interactions determine the destination of the invasive tumor cells in several types of cancer. It has also been proposed that the stromal cell-derived factor-1 (SDF-1; CXCL12)/CXCR4 system might be involved lymph node metastasis in oral squamous cell carcinoma (SCC). In order to further clarify the role of the SDF-1/CXCR4 system in oral SCC, we generated CXCR4 stable transfectants (IH-CXCR4) using oral SCC cells, and compared them to IH, which did not express CXCR4 and which did not have lymph node metastatic potentials in vivo. We introduced enhanced green fluorescent protein (GFP) fused-CXCR4 into IH cells, and detected the GFP fluorescence in the cytoplasm and cell membrane in approximately $60 \%$ of the G418-resistant cells. This bulk-transfectant expressed a high level of CXCR4 mRNA and protein, and exhibited the characteristic calcium fluxes and chemotactic activity observed in treatment with SDF-1. SDF-1 biphasically activated extracellular signal-regulated kinase (ERK)1/2, but continuously activated Akt/protein kinase B (PKB) in IH-CXCR4 cells. Most importantly, IH-CXCR4 cells frequently metastasized to the cervical lymph node, but not to the distant organs in the orthotopic inoculation of nude mice. Furthermore, these lymph node metastases were inhibited by the treatment of a mitogenactivated protein kinase/ERK kinase inhibitor, U0126, or a phosphatidylinositol 3 kinase inhibitor, wortmannin. These results indicate that SDF-1/CXCR4 signaling mediates the establishment of lymph node metastasis in oral SCC via ERK1/2 or Akt/PKB pathway.

Laboratory Investigation (2004) 84, 1538-1546, advance online publication, 11 October 2004; doi:10.1038/labinvest.3700190
\end{abstract}

Keywords: oral SCC; lymph node metastasis; CXCR4; SDF-1; ERK1/2; Akt/PKB

Chemokines are a large family of small $(7-15 \mathrm{kDa})$, structurally related heparin-binding proteins that have been identified as attractants of different types of blood leukocytes to sites of infection and inflammation. ${ }^{1,2}$ Chemokines are also known to function as regulatory molecules in leukocyte maturation, in the trafficking and homing of $\mathrm{T}$ and B lymphocytes, in the development of lymphoid tissues, and in dendritic cell maturation. ${ }^{1,2}$ They are produced locally in the tissues and act on leukocytes through selective membrane-bound GPCRs whose two major subfamilies are designated CCR

Correspondence: Dr D Uchida, PhD, DDS, Second Department of Oral and Maxillofacial Surgery, Tokushima University School of Dentistry, 3-18-15 Kuramoto, Tokushima 770-8504, Japan.

E-mail: daisuke@dent.tokushima-u.ac.jp

Received 13 April 2004; revised 23 August 2004; accepted 28 August 2004; published online 11 October 2004 and CXCR. Among these chemokines and their receptors, the stromal cell-derived factor-1 (SDF-1; also called as CXCL12)/CXCR4 system has been demonstrated to be involved in the lymph node or distant metastasis of several types of cancer, such as breast, ${ }^{3}$ ovary, ${ }^{4}$ prostate, ${ }^{5}$ kidney, ${ }^{6}$ brain,${ }^{7}$ lung, ${ }^{8}$ and thyroid. ${ }^{9}$ In addition, it has been considered that concomitant activation of extracellular signal-regulated kinase (ERK)1/2 or Akt/ protein kinase B (PKB) pathways are critical for metastatic process by this system. ${ }^{8,10,11}$ We have also examined the possibility that this system might be involved in the lymph node metastatic process of oral squamous cell carcinoma (SCC) via activation of both the ERK1/2 and Akt/PKB cascades. ${ }^{12}$ Moreover, we have recently found that expression of CXCR4 in oral SCC at the primary site significantly associated with lymph node metastasis, mode of invasion, tumor recurrence and prognosis of the patients. ${ }^{13}$ However, 
in these studies, the mechanism by which CXCR4 confers enhanced metastasis in vivo was not directly addressed.

By administrating CXCR4-neutralizing antibody into tumor-bearing mice, Muller et $a l^{3}$ have shown that lymph node and lung metastasis was mediated by CXCR4 upon the binding of the ligand SDF-1 in breast cancer cells. On the other hand, Murakami et $a l^{14}$ have reported that the transfection of CXCR4 into melanoma cells dramatically enhanced pulmonary metastasis, but that metastasis to the lymph nodes, liver, and kidney was rare in an in vivo nude mice model. However, in our orthotopic inoculation models, CXCR4-expressing oral SCC cells, B88 and $\mathrm{HNt}$ frequently metastasized to cervical lymph nodes, but did not have the potential to metastasize to distant organs. ${ }^{12,15}$ Thus, the role of CXCR4 in lymph node metastasis seemed to be quite different depending on the cancerous tissue or the cancer cell type. In this study, we generated the CXCR4 transfectant in the CXCR4-negative oral SCC cells, $\mathrm{IH}$, and investigated the direct involvement of SDF1/CXCR4 interactions and the concomitant activation of ERK1/2 or Akt/PKB pathways on the lymph node metastasis of oral SCC.

\section{Materials and methods}

\section{Mice and In Vivo Study}

BALB/c nude mice were purchased from CLEA Japan (Osaka, Japan). The mice were maintained under pathogen-free conditions and were handled in accordance with the Guidelines for Animal Experimentation of Tokushima University. The experiments were initiated when the mice were 8 weeks of age and were performed as described previously. ${ }^{15}$ The experimental chemotherapy by use of kinase inhibitors were performed as described previously ${ }^{16,17}$ with slight modifications. Briefly, tumor-bearing nude mice were treated by an intraperitoneal injection of $100 \%$ dimethyl sulfoxide (DMSO; $2.5 \mathrm{ml} / \mathrm{kg}$ ), U0126 (10 mg/kg; Promega, Madison, WI, USA) or wortmannin $(1.5 \mathrm{mg} / \mathrm{kg}$; Sigma, St Louis, MO, USA) twice a week. The mice were killed at day 30 after initiation of the treatment since treatment with U0126 or wortmannin over 30 to 60 days resulted in severe weight loss (approximately $30-40 \%$ ) and sudden death. The tumor volume was estimated by measuring tumor size and using the following formula: tumor volume $=1 / 2 L W^{2}$, where $L$ and $W$ represent the largest diameter, and the smallest diameter, respectively. The presence or absence of lymph node and distant metastasis was confirmed by the hematoxylin-eosin staining.

\section{Cells and Cell Culture}

IH and B88 cells were derived from human oral SCC tumors from patients ${ }^{12}$ and were maintained in
Dulbecco's modified Eagle medium (DMEM) supplemented with $10 \%$ fetal calf serum (FCS), $100 \mu \mathrm{g} /$ $\mathrm{ml}$ streptomycin, and $100 \mathrm{U} / \mathrm{ml}$ penicillin in a humidified atmosphere of $95 \%$ air and $5 \% \mathrm{CO}_{2}$ at $37^{\circ} \mathrm{C}$.

\section{Construction of a Mammalian Expression Vector}

The mammalian expression vector pEGFP-CXCR4 (containing green fluorescence protein (GFP)-human CXCR4 fusion gene) was constructed as follows. pEGFP-C1 (BD Clontech, Palo Alto, CA, USA) was digested with EcoR1 (Takara Biomedicals, Kusatsu, Japan) and Sal1 (Takara Biomedicals). The human CXCR4 cDNA fragment was amplified from B88 cDNA using a pair of specific primer, ECXCR4-UP; cggaattcatggaggggatcagtatatacacttc, XCXCR4-DN; ccgctcgagttagctggagtgaaaacttgaag. This fragment, containing the human CXCR4 open reading frame, EcoR1 site at $5^{\prime}$ end, and Xho1 site at $3^{\prime}$ end, was ligated to the cloning site, which was localized on the downstream of GFP gene of pEGFP-C1. The integrity and fidelity of the cloned sequences were confirmed by use of ALOKA DNA sequencer (ALOKA, Tokyo, Japan).

\section{Transfection and Immunocytochemistry}

Cells $\left(5 \times 10^{5}\right.$ cells/dish $)$ were seeded in $100 \mathrm{~mm}$ culture dishes (Falcon; Becton Dickinson Labware, Lincoln Park, NJ, USA) in DMEM supplemented with $10 \%$ FCS. After $24 \mathrm{~h}$, the cells were trypsinized, washed and suspended in $\mathrm{HeBs}(20 \mathrm{mM}$ HEPES, $137 \mathrm{mM} \mathrm{NaCl}, 5 \mathrm{mM} \mathrm{KCl}, 0.7 \mathrm{mM} \mathrm{Na}_{2} \mathrm{HPO}_{4}$, $6 \mathrm{mM}$ glucose). Then the cells resuspended in the same buffer were transfected with $10 \mu \mathrm{g}$ of pEGFPCXCR4 by electroporation (100 V, $99 \mathrm{~ms}, 1$ pulse), using ELECTRO SQUARE PORATOR T820 (BTX Inc., San Diego, CA, USA). The cells were then incubated for $24 \mathrm{~h}$ in DMEM containing $10 \%$ FCS, and then trypsinized and seeded at a 1:5 ratio in $100 \mathrm{~mm}$ culture dishes in DMEM medium containing $10 \%$ FCS. After $48 \mathrm{~h}$, the cells were switched to a selective medium containing Geneticin $(400 \mu \mathrm{g} / \mathrm{ml}$ G418; Life Technologies, Inc., Gaithersburg, MD, USA). Since parental IH cells were quite heterogeneous, all of the G418 resistant clones were collected to avoid the clonal heterogeneity, after 14 days of cultivation in the selective medium. We confirmed the GFP fluorescence in $60 \%$ of the cells by a fluorescent microscopy (Nikon, Tokyo, Japan), and Alexa 594-conjugated ConcanavalinA (ConA; Molecular Probes, Eugene, OR, USA) were used for detection of the cell membrane for $5 \mathrm{~min}$, at $4^{\circ} \mathrm{C}$. After washing the cells with Dulbecco's phosphatebuffered saline (D-PBS $(-)$ ), the cells were fixed with $4 \%$ paraformaldehyde for $10 \mathrm{~min}$. Then, the cells were stained with $2 \mu \mathrm{g} / \mathrm{ml}$ of $4^{\prime}, 6$-diamidino-2phenylindole (DAPI; Roche Molecular Biochemicals, Mannheim, Germany) in D-PBS(-), and 
were mounted with ProLong Antifade (Molecular Probes).

\section{Reverse Transcriptase-Polymerase Chain Reaction (RT-PCR)}

Cells (IH, IH-CXCR4, B88) grown in monolayers were harvested at early confluence. The preparation of cytoplasmic RNA, reverse transcription, and PCR was performed under conditions as described previously. ${ }^{12}$

\section{Flow Cytometric Analysis}

Logarithmically growing oral SCC cells were trypsinized and fixed in $4 \%$ paraformaldehyde on ice for 10 min. The cells were washed and incubated with anti-human CXCR4 monoclonal antibody (mAb; dilution 1:100; MAB173; R\&D, Minneapolis, MN, USA) for $30 \mathrm{~min}$ at room temperature. After being washed twice with D-PBS(-), the cells were incubated with PE-labeled goat anti-mouse IgG (Serotec, Sapporo, Japan) for $30 \mathrm{~min}$ at room temperature and analyzed with an EPICS flow cytometer (Coulter, San Jose, CA, USA).

\section{Calcium Flux Assay}

Calcium flux was performed using a flow cytometer as described previously. ${ }^{12}$ Briefly, the cells were washed with D-PBS $(-)$ and trypsinized. After centrifugation, the cells were resuspended at $1 \times 10^{6} / \mathrm{ml}$ in Hank's balanced salt solution (HBSS) containing Fluo3-AM and Pluronic F-127 (4 $\mu \mathrm{M}$ and $400 \mu \mathrm{g} / \mathrm{ml}$, respectively; Dojindo, Kumamoto, Japan) and incubated for $30 \mathrm{~min}$ at $37^{\circ} \mathrm{C}$. After being washed three times with HEPES-buffered saline $\left(100 \mathrm{mM} \mathrm{NaCl}, 5 \mathrm{mM} \mathrm{KCl}, 1 \mathrm{mM} \mathrm{Na} \mathrm{HPO}_{4}, 5 \mathrm{mM}\right.$ glucose, $0.5 \mathrm{mM} \mathrm{MgCl}_{2}, 10 \mathrm{mM} \operatorname{HEPES}(\mathrm{pH} 7.5$ ), $1 \mathrm{mg} / \mathrm{ml}$ bovine serum albumin, and $1 \mathrm{mM} \mathrm{CaCl}_{2}$ ), the cells were resuspended in $1 \mathrm{ml}$ of the same buffer. The tube was then run for $20 \mathrm{~s}$, and acquisition was stopped. The cells were treated with 100 $\mathrm{ng} / \mathrm{ml}$ of SDF- $1 \alpha$, and acquisition was restarted.

\section{In Vitro Cell Migration Assay}

The in vitro migration of oral SCC cells was evaluated using the Transwell (CORNING, Corning, NY, USA) as described previously. ${ }^{12}$ Oral SCC cells $\left(5 \times 10^{4}\right.$ cells $)$ were seeded on the upper chambers $(6.5 \mathrm{~mm}$ in diameter) with or without $0-100 \mathrm{ng} / \mathrm{ml}$ of SDF-1 $\alpha$ (R\&D) in the lower compartment. After a 12-h incubation, the cells on the upper surface of the membrane were wiped out with a cotton swab, and the membrane was removed from the chamber and stained with hematoxylin-eosin. In some experiments, cells were preincubated with MEK inhibitor, U0126 $(20 \mu \mathrm{M})$ or phosphatidylinositol 3 kinase
(PI3 K) inhibitor wortmannin $(10 \mu \mathrm{M})$ before addition to the upper chamber. The plugged cells in the pore or the cells attached to the lower surface of the membrane were counted in 10 fields at high power view $(\times 400)$ by a third person without any knowledge of the treatments.

\section{Immunohistochemistry}

Metastatic lymph nodes from tumor-bearing nude mice were routinely fixed with formalin and embedded in paraffin. Before staining, $4 \mu \mathrm{m}$ thick sections that were mounted on poly-L-lysine-coated slides were deparaffinized with xylene and rehydrated in graded ethanol. For the purpose of antigen retrieval, the sections were incubated in Target retrieval solution (DAKO, Carpinteria, CA, USA) at $95^{\circ} \mathrm{C}$ for $20 \mathrm{~min}$. After blocking with $3 \%$ horse serum in D-PBS(-), the samples were incubated at room temperature for $1 \mathrm{~h}$ with anti-CXCR4 mAb (12G5; BioSource International, Inc., Camarillo, CA, USA), antiphosphorylated ERK1/2 or Akt/PKB Ab diluted to $1: 100$ with the blocking solution. For the subsequent steps, the avidin-biotin-peroxidase method with a Vectastain ABC kit (Vector, Burlingame, CA, USA) was used.

\section{Western Blotting}

Oral SCC cells were seeded at a density of $1 \times 10^{5}$ cells per $60 \mathrm{~mm}$ culture dish. After stimulation of SDF-1 $\alpha$ with or without synthetic inhibitors as indicated, the cells were lysed with a buffer containing $50 \mathrm{mM}$ Tris-HCl (pH 7.5), $150 \mathrm{mM} \mathrm{NaCl}$, $1 \%$ Nonidet P-40, $0.5 \%$ sodium deoxycholate, a protease inhibitor cocktail tablet (Roche Molecular Biochemicals), and a phosphatase inhibitor cocktail II (Sigma, St Louis, MO, USA). The lysates underwent centrifugation at $12000 \mathrm{~g}$ for $10 \mathrm{~min}$ at $4^{\circ} \mathrm{C}$ and the resultant pellets were discarded. Aliquots of the supernatant containing $50 \mu \mathrm{g}$ protein were analyzed by $10 \%$ SDS-polyacrylamide gel electrophoresis. The separated proteins were transferred to a nitrocellulose membrane (Amersham Pharmacia Biotech, Uppsala, Sweden), and the membrane was incubated with primary Abs, followed by horseradish peroxidase-conjugated secondary Abs. Detection was then performed using an enhanced chemiluminescence kit (Amersham Pharmacia Biotech). All of the primary Abs to phosphorylated and unphosphorylated forms of ERK1/2 and Akt/PKB were purchased from Cell Signaling Technology (Beverly, MA, USA). In case of the tumor tissue formed in the masseter muscle, tumor mass was possibly prepared from surrounding the muscle tissue, followed by homogenized in $50 \mu \mathrm{l}$ of the same lysis buffer described above. After centrifugation at $12000 \mathrm{~g}$ for $20 \mathrm{~min}$ at $4{ }^{\circ} \mathrm{C}$, the supernatant was quantified, and $50 \mu \mathrm{g}$ of the lysate was analyzed by means of the Western blotting. 


\section{Results}

Expression and Localization of GFP-CXCR4 Fusion Protein in the Transfectants

IH cells that were transiently transfected with pEGFP-CXCR4 showed GFP fluorescence only in the cytoplasm and cell membrane but not in the nucleus (Figure 1a), whereas IH cells that were transfected with pEGFP-C1 showed GFP fluorescence both in the cytoplasm and the nucleus (data not shown). After cultivation with selective medium containing G418 for 2 weeks, we collected all the resistant clones for IH-CXCR4 to avoid clonal heterogeneity of the cells. IH-CXCR4 also expressed GFP-CXCR4 fusion protein in the cell membrane and partially in the cytoplasm (Figure 1b-d). Moreover, we could detect the upregulation of CXCR4 mRNA only in the transient and stable transfectant in comparison with parental IH cells (Figure 1e). Next we performed flow cytometric analysis to examine the CXCR4 protein expression. Similar to the RT-PCR results, most of the IH-CXCR4 cells expressed high (75.8\% positive) levels of CXCR4 protein, but parental IH cells (10.5\% positive) expressed this protein at a very low level (Figure 1f).

\section{Functional Expression of GFP-CXCR4 in IH Cells}

To confirm that the expression of CXCR4 in these cells is functional, the cells were treated with the CXCR4 ligand SDF-1 $\alpha$ and calcium fluxes were monitored by flow cytometric analysis. As shown in Figure 2a, recombinant human SDF-1 $\alpha$ treatment rapidly induced characteristic calcium fluxes in $\mathrm{IH}-$ CXCR4 cells, but not in IH cells. Migration assays were performed to examine the effects of SDF- $1 \alpha$ on the motility of the transfectant. Both IH-CXCR4 and endogenous CXCR4 expressing-B88 cells significantly migrate toward $100 \mathrm{ng} / \mathrm{ml}$ of recombinant SDF- $1 \alpha$, but IH cells did not migrate toward the same concentration of SDF-1 $\alpha$ (Figure 2b).

Figure 1 Expression of GFP-CXCR4 in the transfectants. (a) Expression and subcellular localization of GFP-CXCR4 in the transient transfectant of IH cells. (b) Subcellular localization of GFP-CXCR4 in the stable transfectant (green). (c) Cell membrane stained by ConA, Alexa Fluor 594 conjugate (red). (d) Colocalization of GFP-CXCR4 and ConA (yellow). Nucleus was stained with DAPI (blue). (e) Expression of CXCR4 mRNA in the transfectants was detected by use of two pairs of specific primers for CXCR4. CXCR4 SL and CXCR4 FL correspond to the position of 461-761 and 1-1059 in the coding region of CXCR4 mRNA, respectively. Lane1, parental IH cells; Lane2, transient transfectant of GFPCXCR4; Lane3, stable transfectant of GFP-CXCR4; Lane4, negative control (water); Lane5, positive control (B88 cells). (f) Logarithmically growing oral SCC cells were incubated with or without anti-CXCR4 mAb. The cells were then incubated with PE-labeled goat anti-mouse IgG and analyzed with flow cytometry to determine the expression of CXCR4 protein. Clear zones and dark zones show the cells stained by secondary Abs only and antiCXCR4 mAb, respectively. Scale bar, $20 \mu \mathrm{m}(\mathbf{a}-\mathbf{d})$.

Signal Transduction Involved in the SDF-1/CXCR4 System on Oral SCC

In our previous study, $\mathrm{SDF}-1 \alpha$ rapidly activated ERK1/2 and Akt/PKB signaling pathways in B88 cells. ${ }^{12}$ To study the contribution of these kinases in the SDF-1/CXCR4 system on IH-CXCR4 cells, we incubated IH-CXCR4 cells for different amounts of time with SDF-1 $\alpha$, and examined changes in the phosphorylation of ERK1/2 and Akt/PKB by Western blotting using Abs that recognize the
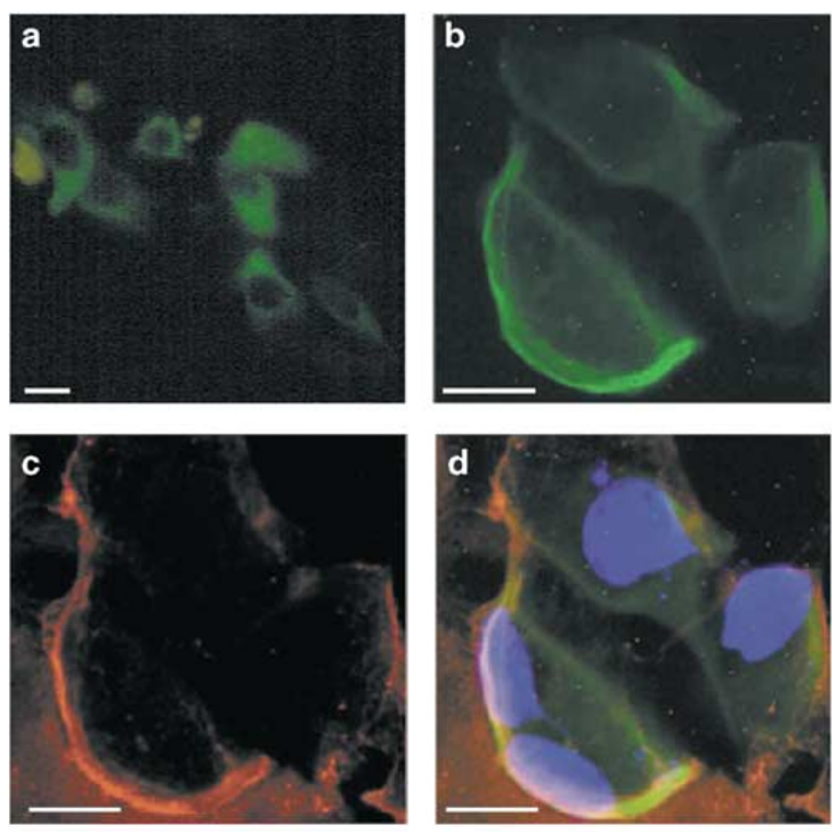

e
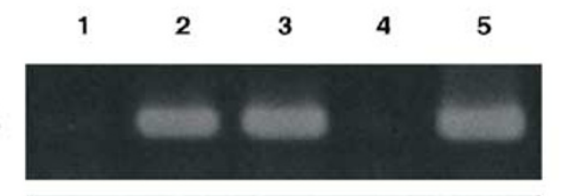

CXCR4 FL

CXCR4 SL

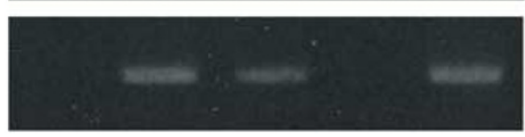

GAPDH

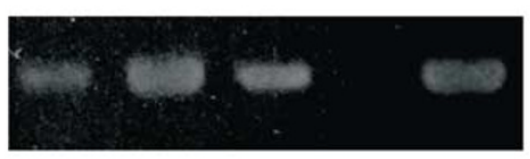

\section{f}

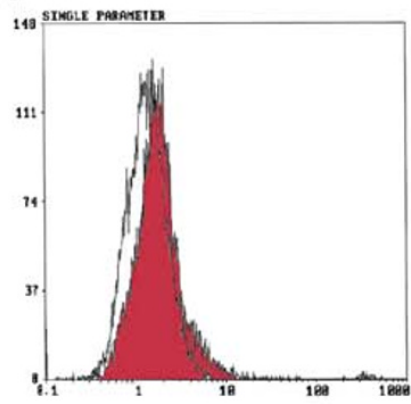

IH

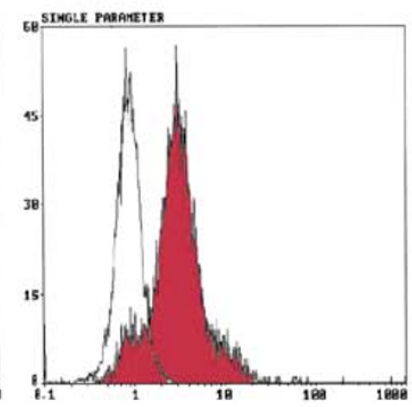

IH-CXCR4 
a

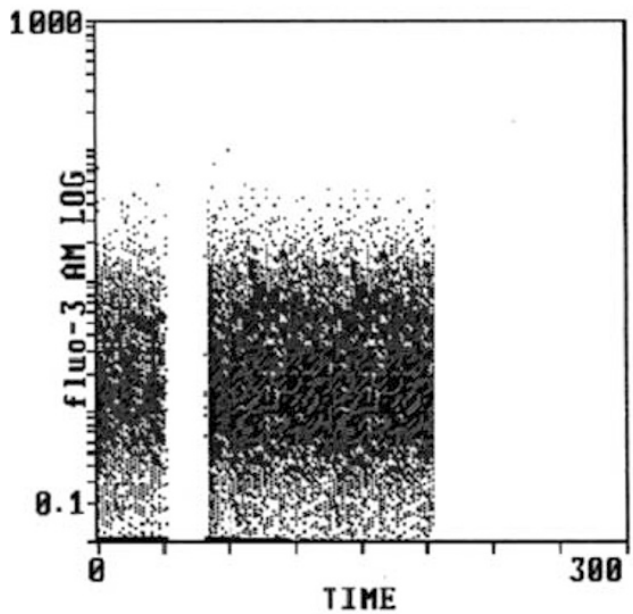

IH-CXCR4

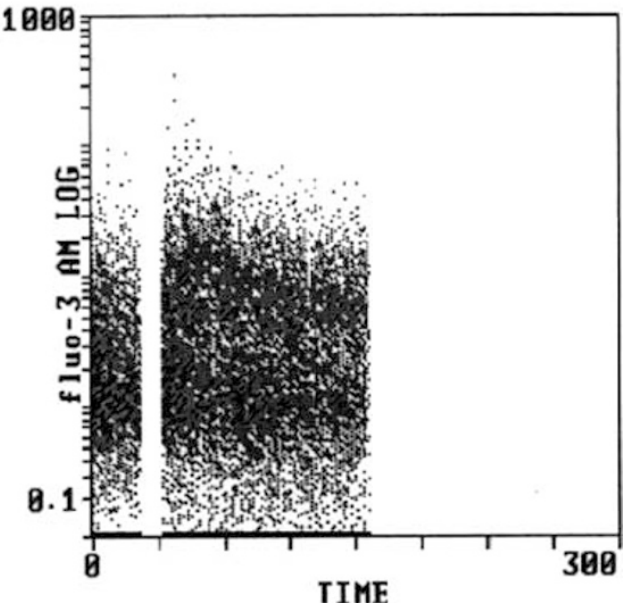

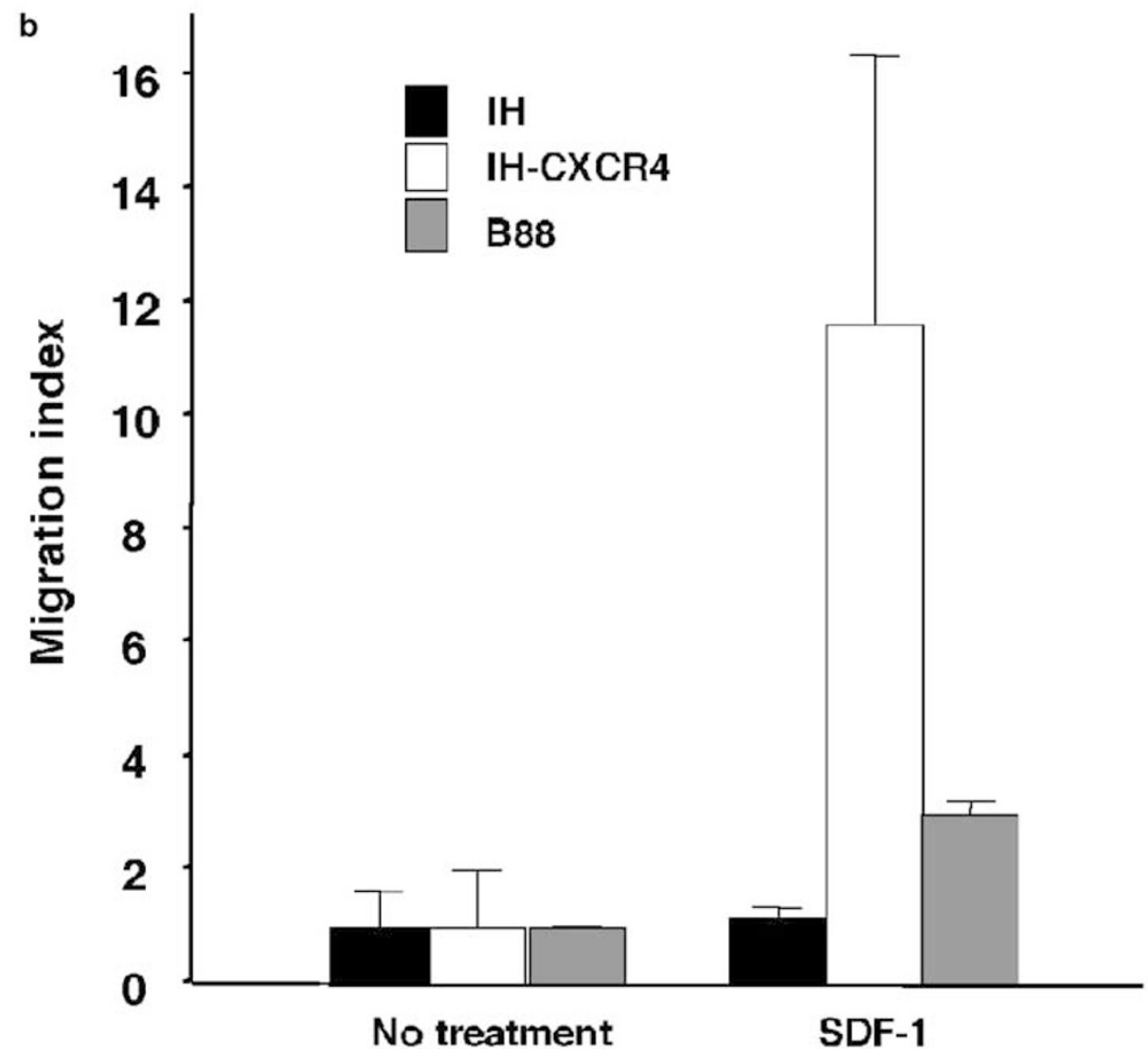

Figure 2 Functional expression of GFP-CXCR4 in the transfectants. (a) $\mathrm{Ca}^{2+}$ flux on logarithmically growing $\mathrm{IH}$ (left panel) and IHCXCR4 (right panel) cells in response to SDF- $1 \alpha(100 \mathrm{ng} / \mathrm{ml})$ were determined with flow cytometry at $525 \mathrm{~nm}$. Arrow indicates the addition of SDF-1 $\alpha$. (b) IH (black box), IH-CXCR4 (white box), and B88 (gray box) cells were seeded on the upper membrane in the presence or absence of the indicated concentrations of SDF- $1 \alpha$ in the lower compartment. After $12 \mathrm{~h}$, the cells attached to the undersurface of the membrane were stained by hematoxylin-eosin and counted. The bars show the SD of triplicate samples. Data are representative of three separate experiments with similar results. ${ }^{*} P<0.01$ when compared to that of the control by one-way ANOVA.

phosphorylated form of these kinases. SDF- $1 \alpha$ biphasically upregulated the phosphorylated form of ERK $1 / 2$ on IH-CXCR4 cells, at $2 \mathrm{~min}$ and $3 \mathrm{~h}$ (Figure 3a). The activation of ERK1/2 by SDF-1 $\alpha$ in intrinsically CXCR4-expressing oral SCC cells, B88, seemed to be biphasic, but the level was faintly detectable. On the other hand, although Akt/PKB was also phosphorylated at Ser473 by the SDF-1 $\alpha$, the activation was linear rather than biphasic in both cell types (Figure 3b). Next, we examined the 
IH-CXCR4

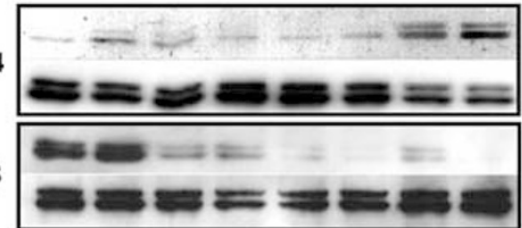

PERK $1 / 2$

ERK1/2

pERK1/2

ERK1/2

b

$\begin{array}{lllllllll}0 & 2 & 10 & 30 & 60 & 120 & 180 & 240 & \text { Time (min) }\end{array}$

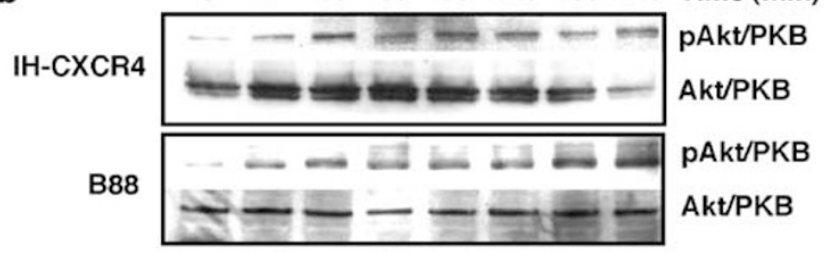

C

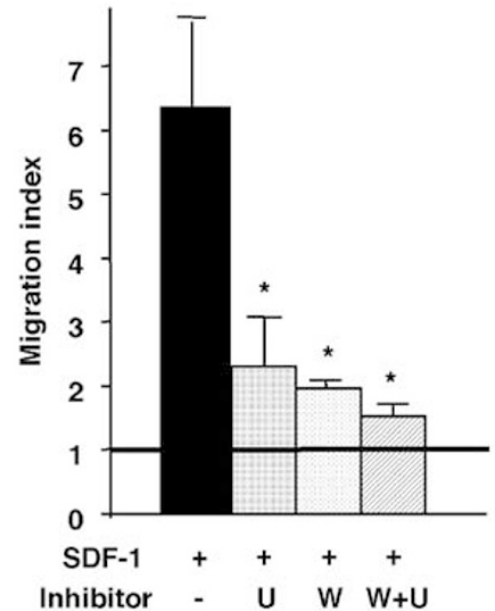

Figure 3 Signal transduction of IH-CXCR4 cells mediated by SDF1 stimulation. (a) Serum-starved IH-CXCR4 or B88 cells were incubated with $100 \mathrm{ng} / \mathrm{ml}$ SDF- $1 \alpha$ for the times indicated. Cell lysates were probed with phosphorylated and total ERK1/2 Abs. (b) Serum-starved IH-CXCR4 or B88 cells were incubated with $100 \mathrm{ng} / \mathrm{ml}$ SDF- $1 \alpha$ for the times indicated. Cell lysates were probed with phosphorylated (Ser473) and total Akt/PKB Abs. All the data are representative of three separate experiments with similar results. (c) IH-CXCR4 cells were pretreated with indicated inhibitors for $45 \mathrm{~min}$ and were seeded on the upper membrane with or without $100 \mathrm{ng} / \mathrm{ml} \mathrm{SDF-1} \alpha$ in the lower compartment. After $24 \mathrm{~h}$, attached cells were stained by hematoxylin-eosin and counted. Chemotactic index shows the values that were compensated by each set of the data without addition of SDF- $1 \alpha$. The bars show the SD of triplicate samples. Data are representative of two separate experiments with similar results. ${ }^{*} P<0.001$ when compared to the data with addition of SDF- $1 \alpha$ alone by one-way ANOVA. U; U0126, W; wortmannin.

effect of a MEK inhibitor, U0126, or a PI3 K inhibitor, wortmannin on the cell migration of IH-CXCR4 induced by SDF-1. Although U0126 and/or wortmannin inhibited the migration of the cells in compared with the no-treatment control, probably due to cytotoxic effects of these inhibitors, these inhibitors significantly suppressed the SDF-1induced migration of IH-CXCR4 cells in compared with the addition of these inhibitors alone $(P<0.001$; Figure 3c). These results indicate that both ERK1/2 and Akt/PKB pathways were indispensable for SDF-1/CXCR4-induced chemotaxis.
Table 1 Summary of the result at day 60 after orthotopic inoculation of nude mice

\begin{tabular}{|c|c|c|c|c|}
\hline \multirow[t]{2}{*}{ Cells } & \multirow[t]{2}{*}{ Tumorigenicity } & \multirow{2}{*}{$\begin{array}{l}\text { Tumor volume } \\
\qquad\left(L W^{2} / 2\right)\end{array}$} & \multicolumn{2}{|c|}{ Metastasis } \\
\hline & & & $\begin{array}{c}\text { Cervical } \\
\text { lymph }\end{array}$ & Lung \\
\hline $\mathrm{IH}$ & $3 / 5$ & $25.1 \pm 37.3$ & $0 / 5$ & $0 / 5$ \\
\hline IH-CXCR4 & $3 / 5$ & $27.4 \pm 36.1$ & $4 / 5$ & $0 / 5$ \\
\hline
\end{tabular}

\section{Acquisition of Lymph Node Metastatic Potential in the IH-CXCR4 Cells In Vivo}

To assess the involvement of lymph node metastasis in the overexpression of CXCR4 in IH cells, IHCXCR4 cells were orthotopically inoculated into the masseter muscle of nude mice. The mice inoculated with IH cells formed tumors in the masseter muscle (3/5), but neither lymph node nor distant metastasis were observed (at the ratio of $0 / 5$; Table 1 ). In contrast, cervical lymph node metastasis was frequently observed in the mice inoculated with $\mathrm{IH}$ CXCR4 cells (at the ratio of 4/5; Table 1; Figure 4a). However, distant metastasis, including the lung and, liver, was not observed even at 90 days after inoculation of the cells (data not shown). Moreover, most of the metastatic IH-CXCR4 cells strongly expressed CXCR4 protein in the cytoplasm (Figure 4b). Surprisingly, lymph node metastasis was observed even in one of two cases where the primary tumor had disappeared. In addition, although both $\mathrm{IH}$ and IH-CXCR4 cells formed tumors in the masseter muscles of nude mice, there was no difference in the primary tumor size between the two (Table 1).

\section{Involvement of ERK1/2 and Akt/PKB Pathways on the SDF-1/CXCR4 System In Vivo}

In the orthotopic inoculation of IH-CXCR4, some of the metastatic cancer cells expressed activated ERK1/2 (Figure 4c) or Akt/PKB (Figure 4d) both in the cytoplasm and nucleus. In order to assess the direct involvement of activation of ERK1/2 or Akt/ PKB on the lymph node metastasis of IH-CXCR4, we treated the IH-CXCR4 tumor-bearing mice with U0126 or wortmannin. These kinase inhibitors effectively inhibited the activation of ERK1/2 (especially ERK1) or Akt/PKB in the primary tumor (Figure 4e). Moreover, these kinase inhibitors did not affect the growth of IH-CXCR4 cells at the primary site; however, they decreased the appearance rate of lymph node metastasis rather than vehicle DMSO (Table 2). These results suggest that expression of CXCR4 are involved in the lymph node metastasis of oral SCC cells via ERK1/2 and Akt/PKB pathways. 

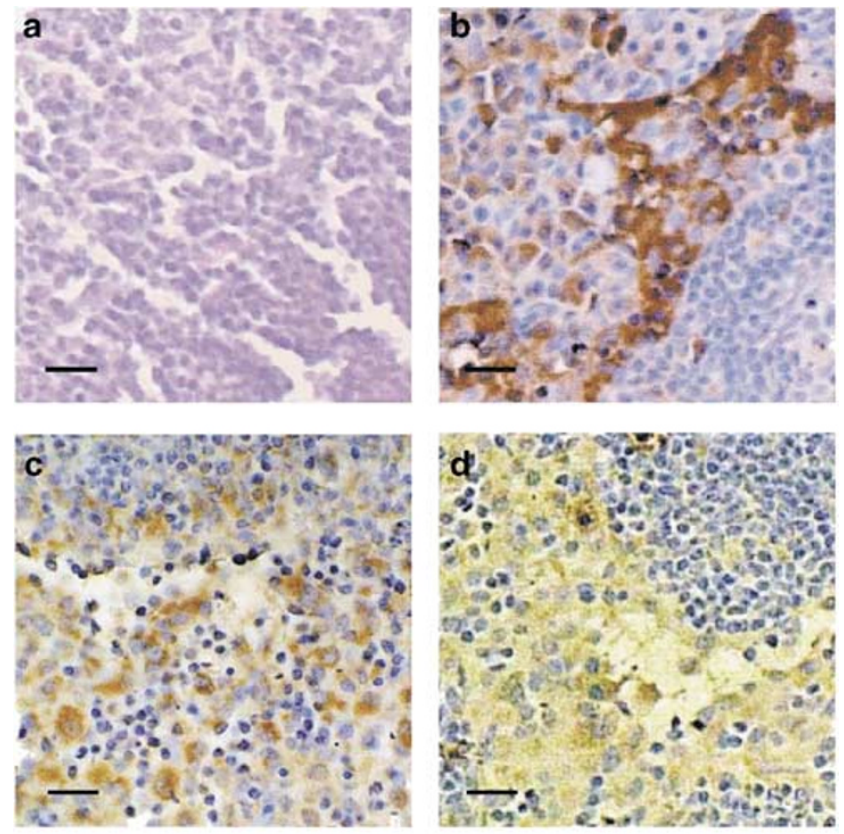

e
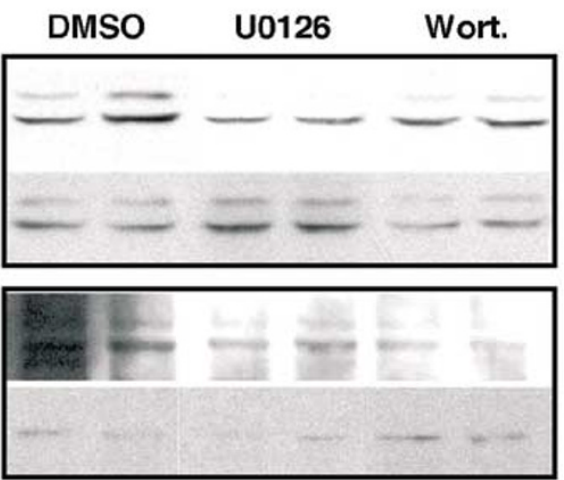

pERK1/2

ERK1/2

pAkt/PKB

Akt/PKB

Figure 4 Lymph node metastasis in IH-CXCR4 cells. IH-CXCR4 cells $\left(5 \times 10^{6}\right)$ were inoculated into the masseter muscle of nude mice, which were killed at day 60. Lymph nodes were fixed and embedded, and then stained by hematoxylin-eosin (a), immunostained by anti-CXCR4 mAb (b), phosphorylated ERK1/2 Ab (c) and phosphorylated Akt/PKB Ab (d). Scale bar, $50 \mu \mathrm{m}$. (e) IHCXCR4 tumor-bearing nude mice were treated by DMSO $(2.5 \mathrm{ml} /$ $\mathrm{kg})$, U0126 (10 mg/kg) or wortmannin $(1.5 \mathrm{mg} / \mathrm{kg})$ twice a week for 30 days. The tumor lysates from representative two mice treated by each inhibitor were subjected to the Western blotting. Data are representative of two separate experiments with similar results.

\section{Discussion}

The chemokine receptor CXCR4 and its cognate ligand SDF- $1 \alpha$ have recently gained considerable interest because of their role in B-cell lymphopoiesis, bone marrow myelopoiesis, vascular development, cardiogenesis and HIV pathogenesis. ${ }^{18-21}$ More recently, this receptor-ligand system has been reported to determine the destination of tumor cells such as breast cancer cells, ovarian cancer cells, prostate cancer cells, neuroblastoma cells and malignant melanoma cells. To address the direct affect on this gradient, Muller et $a l^{3}$ and Philips
Table 2 Summary of the result at day 30 after the experimental chemotherapy for IH-CXCR4 tumor-bearing nude mice

\begin{tabular}{lclc}
\hline \multirow{2}{*}{ Treatments } & $\begin{array}{c}\text { Tumor volume } \\
\left(L W^{2} / 2\right)\end{array}$ & \multicolumn{2}{c}{ Metastasis } \\
\cline { 3 - 4 } & & $\begin{array}{c}\text { Cervical } \\
\text { lymph }\end{array}$ & Lung \\
& & $6 / 8$ & $0 / 8$ \\
\hline DMSO $(2.5 \mathrm{ml} / \mathrm{kg})$ & $22.3 \pm 15.3$ & $1 / 7$ & $0 / 7$ \\
U0126 $(10 \mathrm{mg} / \mathrm{kg})$ & $19.6 \pm 13.0$ & $2 / 7$ & $0 / 7$ \\
Wortmannin $(1.5 \mathrm{mg} / \mathrm{kg})$ & $25.1 \pm 12.8$ & & \\
\hline
\end{tabular}

et $a 1^{22}$ independently administered specific neutralizing anti-CXCR4 antibody or anti-SDF-1 antibody, respectively, to tumor-bearing mice, and found the abrogated-organ metastases. However, administration of neutralizing antibody to the nude mice has drawbacks, such as determination of the optimal antibody concentration and the occurrence of side effects in the hematopoietic cells or in the CXCR4expressing endothelial cells around the tumor cells. Thus, to assess the direct involvement of the SDF-1 gradient on the lymph node metastasis of CXCR4expressing oral SCC, we transfected a GFP-CXCR4 expression vector into IH cells, which did not express CXCR4, and which did not have lymph node metastatic potentials in vivo. In-frame fusion of the target gene with GFP is a powerful tool for a study of subcellular localization, protein translocation, receptor internalization, and recycling receptor endocytosis in real time in living cells. ${ }^{23,24}$ In the case of CXCR4, fusion of the GFP with CXCR4 was previously found to produce fully functional CXCR4 ${ }^{25,26}$ In the present study, we also used the GFP-CXCR4 construct and found a subcellular localization of CXCR4 in T cells that was similar to that shown by Tarasova et al. ${ }^{25}$ Moreover, by means of a calcium flux assay, IH cells expressing GFPCXCR4 were functionally responded to by its ligand, SDF-1, indicating that our GFP-CXCR4 construct was functionally worked in IH cells.

We have already reported that SDF-1 rapidly activated both ERK1/2 and Akt/PKB in intrinsically CXCR4-expressing oral SCC cells, B88. ${ }^{12}$ In the present study, we found not only rapid activation of both ERK1/2 but also late activation of this kinase faintly in B88 and strongly in IH-CXCR4 cells. Han et $a l^{27}$ have observed similar results in the primary astrocytes, in which early ERK1/2 activation was stimulated directly by SDF- $1 \alpha$ and late activation was mediated by TNF- $\alpha$-stimulated NF- $\kappa$ B activation induced by SDF-1 $\alpha$. Moreover, Scotton et $a 1^{10}$ have also reported that ligand stimulation of the CXCR4 receptor resulted in biphasic phosphorylation of ERK1/2 in ovarian cancer cells. They also speculated on the effect of TNF- $\alpha$ on this biphasic activation of these kinases. However, in our experimental condition, TNF- $\alpha$ was not induced by the treatment of SDF-1 both in IH-CXCR4 and B88 cells 
(unpublished data). Moreover, we could not find the activation of NF- $\kappa$ B by the treatment of SDF-1 in B88 cells, ${ }^{12}$ indicating that late activation of ERK1/2 might be mediated by other cytokine signaling(s), which might induce the difference in the late activation level of ERK1/2 between B88 cells and IH-CXCR4 cells (Figure 3a). Although Akt/PKB was also found to be phosphorylated at Ser473 by the SDF-1 $\alpha$, unlike ERK1/2, the activation was linear in both cell types. It has been demonstrated that SDF-1 induced the prolonged activation of Akt/PKB in ovarian cancer cells ${ }^{10}$ and T cells. ${ }^{28}$ Stimulation of phosphatidyl-3,4,5,-triphosphate (PIP3) formation by $\mathrm{G}$ protein-coupled receptors is considered to be biphasic and to involve two types of PI3 K, PI3K $\gamma$, which is activated by $\beta \gamma$ subunits of heterotrimeric G proteins, ${ }^{29}$ and a p85/p110 isoform, which is activated by tyrosine kinase-regulated pathways. ${ }^{30}$ Moreover, Tilton et $a l^{28}$ also described that the initial prominent peak of Akt/PKB activation by SDF-1/CXCR4 system in T cells is mediated by the $\beta \gamma$ subunit-regulated PI3 K, whereas the more protracted activation is mediated by a p85/110 isoform. Thus, these two types of PI3 $\mathrm{K}$ might mediate sustained activation of Akt/PKB by SDF-1/CXCR4 system in oral SCC cells.

We proposed that both ERK1/2 and Akt/PKB pathways play critical roles on the lymph node metastasis of IH-CXCR4. Although diverse ligandreceptor systems related on lymph node metastasis have been identified, ERK1/2 or Akt/PKB pathways takes part in most of their downstream signaling. For example, Albanell et al ${ }^{31}$ have reported that ERK1/2 activation levels, via epidermal growth factor or transforming growth factor- $\alpha$ pathway, were higher in oral SCC with advanced regional lymph node metastasis and in relapsed tumors. Moreover, recent report suggested that vascular endothelial growth factor $\mathrm{C}$ expression and lymph node metastasis are regulated by the type I insulin-like growth factor receptor via PI3K-Akt/PKB and/or MEK-ERK dependent pathways. ${ }^{32}$ Thus, in our experimental model, kinase inhibitors suppressed all of the ERK1/2 or Akt/PKB pathways activated by the diverse ligandreceptor systems; however, our data might support a new proposal that the activation of ERK1/2 or Akt/ $\mathrm{PKB}$ in the regional lymph node metastasis of oral SCC might be also mediated by SDF-1/CXCR4 interaction.

We observed the frequent cervical lymph node metastasis in the mice inoculated with IH-CXCR4 cells. Kang et $a l^{33}$ have demonstrated that in the case of breast cancer cells, only a small percentage of tumor cells which express metastatic factors, including CXCR4, are important for the bone metastasis. In the IH-CXCR4 cells, not all of the cells express CXCR4, but it may be speculated that tumor cells overexpressing CXCR4 specifically metastasized to the cervical lymph node, since most of the cells in the metastatic lymph node strongly expressed CXCR4 by immunohistochemistry.
Our studies revealed that the overexpression of CXCR4 in oral SCC cells might be sufficient for acquiring lymph node metastatic potential, but not for distant metastatic potential in vivo. Indeed, although lung, liver, bone marrow, and the adrenal gland were also reported to express SDF-1 mRNA, ${ }^{3,22}$ the distant metastasis involved in these organs is clinically very rare in oral SCC. We have previously reported that oral SCC cells easily undergo intravasation despite the establishment of distant metastasis. ${ }^{34}$ Thus, such observations suggest that, for the establishment of distant metastasis in oral SCC, extravasation or ectopic growth potential may be more important than intravasation or angiogenesis, and microenvironmental factors, including adhesion molecules or growth factors, in these organs may not favor the metastasis of the oral SCC cells.

In conclusion, SDF-1 gradient from lymph node toward oral SCC cells expressing CXCR4 play a critical role on lymph node metastasis via ERK1/2 or Akt/PKB pathway. The expression of CXCR4 can be used as a molecular target of diagnosis for oral SCC with lymph node metastatic potential. Furthermore, inhibitors or antagonists against CXCR4, or kinase inhibitors, such as U0126 or wortmannin, might be a way to prevent the lymph node metastasis in patients with oral SCC.

\section{Acknowledgements}

We thank Drs Naozumi Ishimaru and Yoshio Hayashi (Department of Pathology, Tokushima University School of Dentistry) for their valuable histopathologic advice. We also thank Dr Hitoshi Kawamata (Department of Surgical and Molecular Pathology, Dokkyo University School of Medicine) for the valuable advice on the experimental chemotherapy. This study was supported in part by a grantin-aid from the Ministry of Education, Science and Culture of Japan.

\section{References}

1 Rossi D, Zlotnik A. The biology of chemokines and their receptors. Annu Rev Immunol 2000;18:217-242.

2 Zlotnik A, Yoshie O. Chemokine a new classification system and their role in immunity. Immunity 2000; 12:121-127.

3 Muller A, Homey B, Soto $\mathrm{H}$, et al. Involvement of chemokine receptors in breast cancer metastasis. Nature (Lond) 2001;410:50-56.

4 Scotton CJ, Wilson JL, Milliken D, et al. Epithelial cancer cell migration: a role for chemokine receptors? Cancer Res 2001;61:4961-4965.

5 Taichman RS, Cooper C, Keller ET, et al. Use of the stromal cell-derived factor-1/CXCR4 pathway in prostate cancer metastasis to bone. Cancer Res 2002; 62:1832-1837. 
6 Schrader AJ, Lechner O, Templin M, et al. CXCR4/ CXCL12 expression and signalling in kidney cancer. Br J Cancer 2002;86:1250-1256.

7 Zhou Y, Larsen PH, Hao C, et al. CXCR4 is a major chemokine receptor on glioma cells and mediates their survival. J Biol Chem 2002;277:49481-49487.

8 Kijima T, Maulik G, Ma PC, et al. Regulation of cellular proliferation, cytoskeletal function, and signal transduction through CXCR4 and c-Kit in small cell lung cancer cells. Cancer Res 2002;62:6304-6311.

9 Hwang JH, Hwang JH, Chung HK, et al. CXC chemokine receptor 4 expression and function in human anaplastic thyroid cancer cells. J Clin Endocrinol Metab 2003;88:408-416.

10 Scotton CJ, Wilson JL, Scott K, et al. Multiple actions of the chemokine CXCL12 on epithelial tumor cells in human ovarian cancer. Cancer Res 2002;62:5930-5938.

11 Barbero S, Bonavia R, Bajetto A, et al. Stromal cellderived factor 1alpha stimulates human glioblastoma cell growth through the activation of both extracellular signal-regulated kinases $1 / 2$ and Akt. Cancer Res 2003;63:1969-1974.

12 Uchida D, Begum NM, Almofti A, et al. Possible role of stromal cell-derived factor-1/CXCR4 signaling on lymph-node metastasis of oral squamous cell carcinoma. Exp Cell Res 2003;290:289-302.

13 Ammar A, Uchida D, Begum NM, et al. The clinicopathological significance of the expression of CXCR4 protein in oral squamous cell carcinoma. Int J Oncology 2004;25:65-71.

14 Murakami T, Maki W, Cardones AR, et al. Expression of CXC chemokine receptor-4 enhances the pulmonary metastatic potential of murine B16 melanoma cells. Cancer Res 2002;62:7328-7334.

15 Kawamata H, Nakashiro K, Uchida D, et al. Possible contribution of active MMP2 to lymph-node metastasis and secreted cathepsin L to bone invasion of newly established human oral-squamous-cancer cell lines. Int J Cancer 1997;70:120-127.

16 Bondar VM, Sweeney-Gotsch B, Andreeff M, et al. Inhibition of the phosphatidylinositol 3'-kinase-AKT pathway induces apoptosis in pancreatic carcinoma cells in vitro and in vivo. Mol Cancer Ther 2002;1: 989-997.

17 Horiuchi H, Kawamata H, Fujimori T, et al. A MEK inhibitor (U0126) prolongs survival in nude mice bearing human gallbladder cancer cells with K-ras mutation: analysis in a novel orthotopic inoculation model. Int J Oncol 2003;23:957-963.

18 Bleul CC, Farzan M, Choe H, et al. The lymphocyte chemoattractant SDF-1 is a ligand for LESTR/fusin and blocks HIV-1 entry. Nature (Lond) 1996;382:829-833.

19 Nagasawa T, Hirota S, Tachibana K, et al. Defects of B-cell lymphopoiesis and bone-marrow myelopoiesis in mice lacking the CXC chemokine PBSF/SDF-1. Nature (Lond) 1996;382:635-638.

20 Oberlin E, Amara A, Bachelerie F, et al. The CXC chemokine SDF-1 is the ligand for LESTR/fusin and prevents infection by T-cell-line-adapted HIV-1. Nature (Lond) 1996;382:833-835.

21 Aiuti A, Webb IJ, Bleul C, et al. The chemokine SDF-1 is a chemoattractant for human CD34+ hematopoietic progenitor cells and provides a new mechanism to explain the mobilization of CD34+ progenitors to peripheral blood. J Exp Med 1997;185:111-120.

22 Phillips RJ, Burdick MD, Lutz M, et al. The stromal derived factor-1/CXCL12-CXC chemokine receptor 4 biological axis in non-small cell lung cancer metastases. Am J Respir Crit Care Med 2003; 167:1676-1686.

23 Tarasova NI, Stauber RH, Michejda CJ. Spontaneous and ligand-induced trafficking of CXC-chemokine receptor 4. J Biol Chem 1998;273:15883-15886.

24 Hino S, Kawamata H, Uchida D, et al. Nuclear translocation of TSC-22 (TGF-beta-stimulated clone22) concomitant with apoptosis: TSC-22 as a putative transcriptional regulator. Biochem Biophys Res Commun 2000;278:659-664.

25 Tarasova NI, Stauber RH, Choi JK, et al. Visualization of $\mathrm{G}$ protein-coupled receptor trafficking with the aid of the green fluorescent protein. Endocytosis and recycling of cholecystokinin receptor type A. J Biol Chem 1997;272:14817-14824.

26 Van Buul JD, Voermans C, Van Gelderen J, et al. Leukocyte-endothelium interaction promotes SDF-1dependent polarization of CXCR4. J Biol Chem 2003; 278:30302-30310.

27 Han Y, He T, Huang DR, et al. TNF-alpha mediates SDF-1 alpha-induced NF-kappa B activation and cytotoxic effects in primary astrocytes. J Clin Invest 2001;108:425-435.

28 Tilton B, Ho L, Oberlin E, et al. Signal transduction by CXC chemokine receptor 4 . Stromal cell-derived factor 1 stimulates prolonged protein kinase B and extracellular signal-regulated kinase 2 activation in $\mathrm{T}$ lymphocytes. J Exp Med 2000;192:313-324.

29 Stephens L, Smrcka A, Cooke FT, et al. A novel phosphoinositide 3 kinase activity in myeloid-derived cells is activated by $\mathrm{G}$ protein $\beta \gamma$ subunits. Cell 1994; 77:83-93.

30 Ptasznik A, Prossnitz ER, Yoshikawa D, et al. A tyrosine kinase signaling pathway accounts for the majority of phosphatidylinositol 3,4,5-trisphosphate formation in chemoattractant-stimulated human neutrophils. J Biol Chem 1996;271:25204-25207.

31 Albanell J, Codony-Servat J, Rojo F, et al. Activated extracellular signal-regulated kinases: association with epidermal growth factor receptor/transforming growth factor alpha expression in head and neck squamous carcinoma and inhibition by anti-epidermal growth factor receptor treatments. Cancer Res 2001;61: 6500-6510.

32 Tang Y, Zhang D, Fallavollita L, et al. Vascular endothelial growth factor C expression and lymph node metastasis are regulated by the type I insulinlike growth factor receptor. Cancer Res 2003;63: 1166-1171.

33 Kang Y, Siegel PM, Shu W, et al. A multigenic program mediating breast cancer metastasis to bone. Cancer Cell 2003;3:537-549.

34 Kawamata H, Uchida D, Nakashiro K, et al. Haematogenous cytokeratin 20 mRNA as a predictive marker for recurrence in oral cancer patients. Br J Cancer 1999; 80:448-452. 